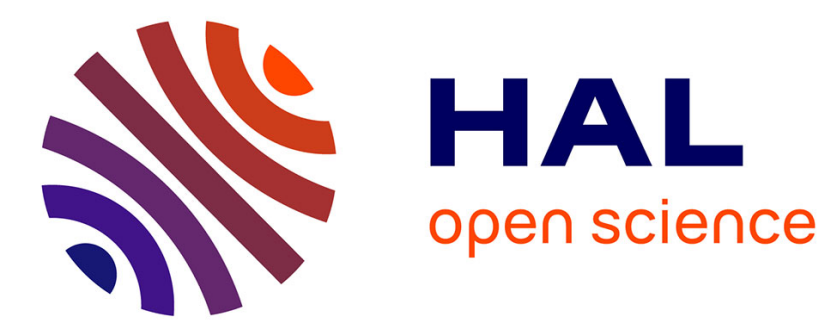

\title{
Calculating with hyperbolas and parabolas
}

Dominique Tournès

\section{To cite this version:}

Dominique Tournès. Calculating with hyperbolas and parabolas. Évelyne Barbin (ed.). Let History into the Mathematics Classroom, Springer, pp.101-114, 2018. hal-01484259

\section{HAL Id: hal-01484259 \\ https://hal.science/hal-01484259}

Submitted on 7 Mar 2017

HAL is a multi-disciplinary open access archive for the deposit and dissemination of scientific research documents, whether they are published or not. The documents may come from teaching and research institutions in France or abroad, or from public or private research centers.
L'archive ouverte pluridisciplinaire HAL, est destinée au dépôt et à la diffusion de documents scientifiques de niveau recherche, publiés ou non, émanant des établissements d'enseignement et de recherche français ou étrangers, des laboratoires publics ou privés.

\section{(이)(\$)}

Distributed under a Creative Commons Attribution - NonCommercial - NoDerivatives| 4.0 


\title{
Calculating with hyperbolas and parabolas
}

\author{
Dominique TOURNĖS \\ IREM et Laboratoire d'informatique et de mathématiques (LIM, EA 2525), Université de la Réunion \\ SPHERE, UMR 7219, CNRS et Université Paris-Diderot
}

\begin{abstract}
Graphical tables (abaques and nomograms) can give rise to original activities for 16 to 18 year olds with a strong historical and cross-curricular element. These activities lend themselves to a practical way of dealing with information and highlighting the changes in presentation (graphic, numerical, algebraic and geometric) as well as offering a motivating topic area for the usual functions required by the programme of study. They also allow the active use of the basic techniques of geometry in an unusual setting. This chapter deals with practical work trialled in a class of 16 year olds, based on two types of multiplication abaques situated in their historical and cultural background: a concurrent-line abaque using a family of hyperbolas and an alignment nomogram with a plotted parabola. The use of these graphical tables allowed the students to revisit their knowledge of inverse square functions, to use freely equations of straight lines and curves, and to anticipate the graphical methods for solving second degree equations.
\end{abstract}

Keywords: Abaque, Nomogram, Hyperbola, Parabola, Multiplication abaque, Multiplication nomogram, Graphical table, Nomography, John Clark, Léon-Louis Lalanne, Julius Mandl, Junius Massau, August Ferdinand Möbius, Maurice d’Ocagne, Louis-Ézéchiel Pouchet.

\begin{abstract}
Abaques and nomograms
Before the widespread use of electronic calculators and computers, people frequently had recourse to numerical tables which brought together the results of numerous calculations carried out once and for all so as to spare the user from repeating tedious calculations. In an analogue way, graphical tables allowed people to find the result of certain calculations with minimum effort. In general, a graphical table appears as a network of marked lines or marked points, with suitably graduated scales, moveable or not, giving, simply by reading off, the required value depending on those of the parameters. Without doubt such tables have been in evidence since the Middle Ages on astrolabes and sundials. In any case, the first ones which were specifically designed for calculation are to be found in connection with linear or circular slide rules, these graphic equivalents of the logarithmic tables invented by the British in the $17^{\text {th }}$ century. From the beginning of the $19^{\text {th }}$ century, graphical tables, initially called 'abaques', then 'nomograms', spread progressively in numerous professional bodies (engineers, artillerymen, navigators, industrialists, physicians etc.) to the point of becoming, a century later, the main instruments of graphical calculation. An entirely separate discipline, called 'nomography', even arose around their study and use. Hardly burdensome, scarcely
\end{abstract}


encumbering, and sufficiently precise for current needs and practice, the abaques held sway most of all through the swift calculations they afforded, essential speed for the professionals having to use them in real time for complex formulae.

Nowadays, nomography has seen an inescapable decline, even if it continues to be used in certain areas of activity. Abaques are often found in technical manuals, catalogues of mechanical parts or catalogues of electrical components. Physicians and chemists still use such graphs, for example to calculate quickly the dose of a drug dependent on various parameters to be taken into account such as the sex, age, height or weight of the patient.

The first objective of this chapter is to show that nomography, although belonging chiefly to the past, retains a strong educational interest. In it the teacher can find a rich source of inspiration to devise motivating activities for all levels of ability. By way of illustration, I will describe some of these activities, as they were tried out on a class of 16 year olds.

To study nomography in depth, one can refer to numerous publications by Maurice d'Ocagne, in particular the 1891 work, which fulfilled the role of founding work in the discipline (Ocagne, 1891).

Let us begin by defining the basic mathematical notions which are hidden behind graphical tables. The central problem of nomography is that of the flat two-dimensional representation of the relationships between three variables $\mathrm{F}(\alpha, \beta, \gamma)=0$. The general idea of abaques known as 'concurrent-line abaques', is to make this relationship appear as the result of the elimination of two auxiliary variables between the three equations, each only dependent on one of the three main variables:

$$
\mathrm{F}(\alpha, \beta, \gamma)=0 \Leftrightarrow \exists(x, y)\left\{\begin{array}{l}
\mathrm{F}_{1}(x, y, \alpha)=0 \\
\mathrm{~F}_{2}(x, y, \beta)=0 \\
\mathrm{~F}_{3}(x, y, \gamma)=0
\end{array}\right.
$$

The abaque is therefore formed from three families of marked curves from the respective equations $\mathrm{F}_{1}(x, y, \alpha)=0, \mathrm{~F}_{2}(x, y, \beta)=0$ and $\mathrm{F}_{3}(x, y, \gamma)=0$, drawn on a plane equipped with Cartesian coordinates $x$ and $y$ (Figure 8.1). For each value of the parameter $\alpha$, the first equation determines a curve which is marked on the graph by writing the value of $\alpha$ near to it. Similarly for the other two families.

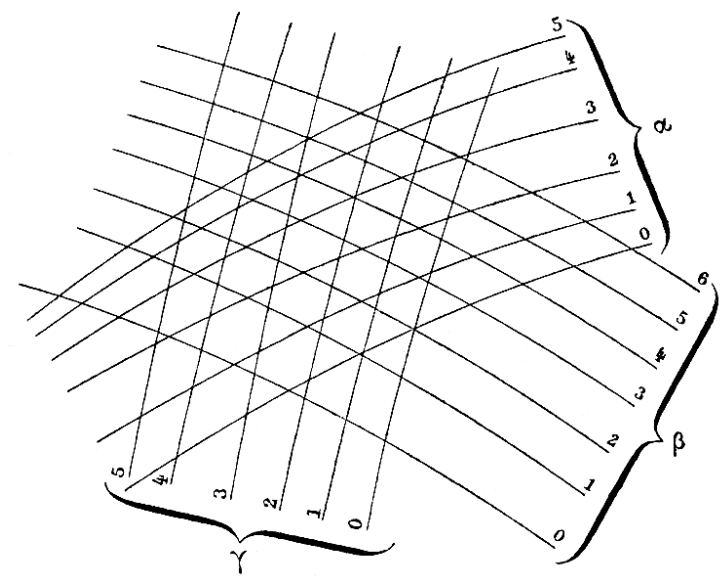

Figure 8.1. Concurrent-line abaque from (Ocagne, 1891). 
On the abaque, a solution $(\alpha, \beta, \gamma)$ of the equation simply corresponds to the crossing at the same point of three curves, one from each family, associated respectively with the values $\alpha, \beta$ and $\gamma$. If we give ourselves the values of any two of the variables, for example $\alpha$ and $\beta$, we find directly the value of the curve from the third family which passes through the crossing point of the curves of the first two families having the values $\alpha$ and $\beta$ (in Figure 8.1, for example, we read $\gamma=2$ when $\alpha=3$ and $\beta=4$ ). In between the values marked on the abaque, we interpolate visually.

The most common approach, which applies to any relationship of the three variables, simply consists of taking $x=\alpha$ and $y=\beta$ for the first two equations. In this case, the curves parameterised by $\alpha$ are parallel to the axis of the ordinates and the curves parameterised by $\beta$ are parallel to the axis of the abscissae. In practice, all that is required is to construct the curves of the equation $\mathrm{F}(\alpha, \beta, \gamma)=0$ on squared paper. It amounts to the topographical representation of a surface by its contour lines. Louis-Ézéchiel Pouchet (1748-1809), a cotton manufacturer from Rouen, was one of the first to employ this idea. In 1795, he represented the multiplication $\alpha \beta=\gamma$ by taking $x=\alpha$ and $y=\beta$, and by drawing the hyperbolas $x y=\gamma$ corresponding to particular values of $\gamma$.

A little later, about 1843, a civil engineer in the Department of Bridges and Highways, Léon-Louis Lalanne (1811-1892) had the idea of geometric anamorphosis: by placing on the axes non-regular graduations, that is by taking $x=\varphi(\alpha)$ and $y=\psi(\beta)$ for the first two equations where $\varphi$ and $\psi$ are suitably chosen functions, one manages in certain cases to make it so that the curves of the third family should also be straight lines. This was how Lalanne managed to turn into straight lines the hyperbolas of equal value used by Pouchet: indeed all it takes is to write $x=\log \alpha$ and $y=\log \beta$ for the equation $\alpha \beta=\gamma$ to become $x+y=\log \gamma$.

In 1884 the Belgian engineer Junius Massau (1852-1909), professor at the University of Ghent, studied more generally the conditions which would allow one to arrive at abaques in which the curves of the three families are straight lines, provided that parallels were no longer used on the coordinate axes. We then talk of 'concurrent-straight-line abaques' (Figure 8.2).

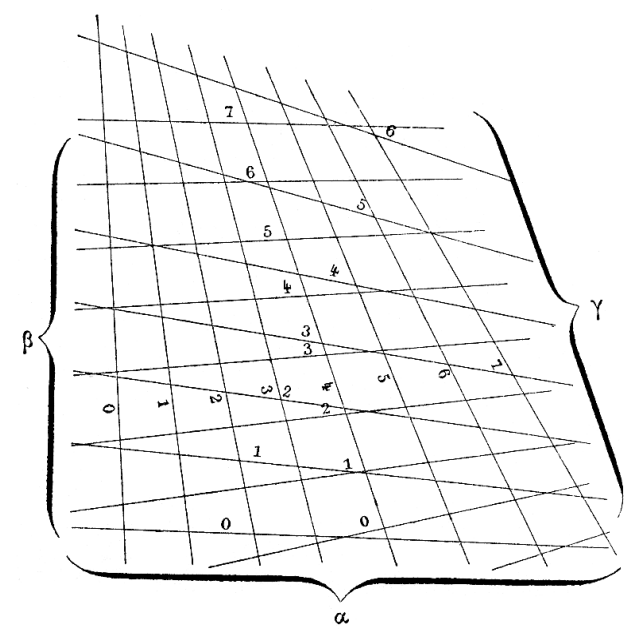

Figure 8.2. Concurrent-straight-line abaque from (Ocagne, 1891). 
When writing that the equations of the three bundles of curves are equations of straight lines, Massau reached the condition

$$
\exists(x, y)\left\{\begin{array}{l}
f_{1}(\alpha) x+g_{1}(\alpha) y+h_{1}(\alpha)=0 \\
f_{2}(\beta) x+g_{2}(\beta) y+h_{2}(\beta)=0 \\
f_{3}(\gamma) x+g_{3}(\gamma) y+h_{3}(\gamma)=0
\end{array} \Leftrightarrow\left|\begin{array}{lll}
f_{1}(\alpha) & g_{1}(\alpha) & h_{1}(\alpha) \\
f_{2}(\beta) & g_{2}(\beta) & h_{2}(\beta) \\
f_{3}(\gamma) & g_{3}(\gamma) & h_{3}(\gamma)
\end{array}\right|=0 .\right.
$$

So when the initial equation $\mathrm{F}(\alpha, \beta, \gamma)=0$ can be placed in such a determinant, called 'Massau's determinant', it can be represented by a concurrent-straight-line abaque.

The following advancement in nomography happens in 1884 when Philibert Maurice d'Ocagne (1862-1938), a young engineer in the Department of Bridges and Highways, imagines a new type of abaque. By exploiting the advances in projective geometry, notably the principle of duality, he transforms the concurrent-straight-line abaques into abaques with aligned points. Indeed, if the nullity of Massau's determinant expresses the concurrence of three straight lines, this nullity equally expresses the alignment of three points, that is the points of the parameters $\alpha, \beta$ and $\gamma$ taken respectively on the parameterised curves

$$
\left\{\begin{array}{l}
x=\frac{f_{1}(\alpha)}{h_{1}(\alpha)} \\
y=\frac{g_{1}(\alpha)}{h_{1}(\alpha)}
\end{array},\left\{\begin{array} { l } 
{ x = \frac { f _ { 2 } ( \beta ) } { h _ { 2 } ( \beta ) } } \\
{ y = \frac { g _ { 2 } ( \beta ) } { h _ { 2 } ( \beta ) } }
\end{array} \text { and } \left\{\begin{array}{l}
x=\frac{f_{3}(\gamma)}{h_{3}(\gamma)} \\
y=\frac{g_{3}(\gamma)}{h_{3}(\gamma)}
\end{array}\right.\right. \text {. }\right.
$$

Thus the three systems of marked straight lines become three marked curves, forming what d'Ocagne calls an 'alignment nomogram' (Figure 8.3). To solve an equation $\mathrm{F}(\alpha, \beta, \gamma)=0$ represented by such a nomogram is simple: if, for example, the values of $\alpha$ and $\beta$ are given, one draws a straight line passing through the marked points $\alpha$ and $\beta$ on the first two curves and this straight line meets the third curve at a point whose value is $\gamma$. In practice, so as not to spoil the abaque, the line is not actually drawn on the paper: one either uses a transparency marked with a fine straight line, or a thin thread which one stretches between the points to be joined.

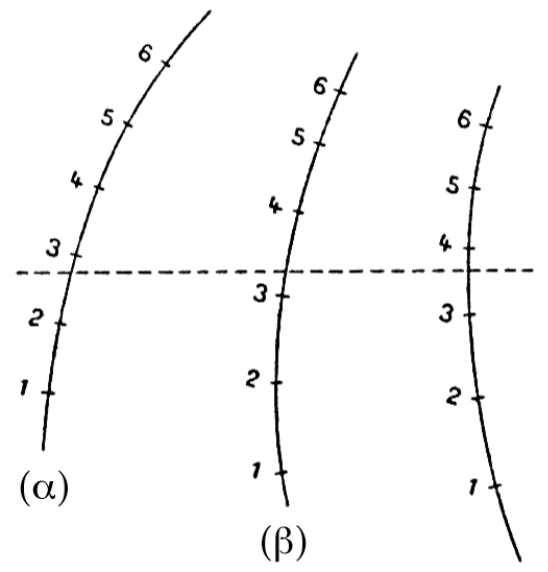

$(\gamma)$

Figure 8.3. Alignment nomogram from (Ocagne, 1891). 
The alignment nomograms are easier to read and, most of all, take up less space than the old concurrent-line abaques which allows for the setting out of several on the same piece of paper. If d'Ocagne introduced the new term 'nomogram' it was mainly to distinguish himself from his predecessors. Later, some authors continued to use the word 'abaque' to indicate any kind of graphical table. From the start of the $20^{\text {th }}$ century, alignment nomograms won the day through their ease of constructions and use, and became the most widespread abaques in all areas. Some still remain in current use, like the one in Figure 8.4, which allows a physician to evaluate quickly the bodily surface area of an adult patient according to height and weight (the line marked on the figure shows, for example, that a patient $170 \mathrm{~cm}$ tall weighing $65 \mathrm{~kg}$ has a body surface area of $1.75 \mathrm{~m}^{2}$ ).

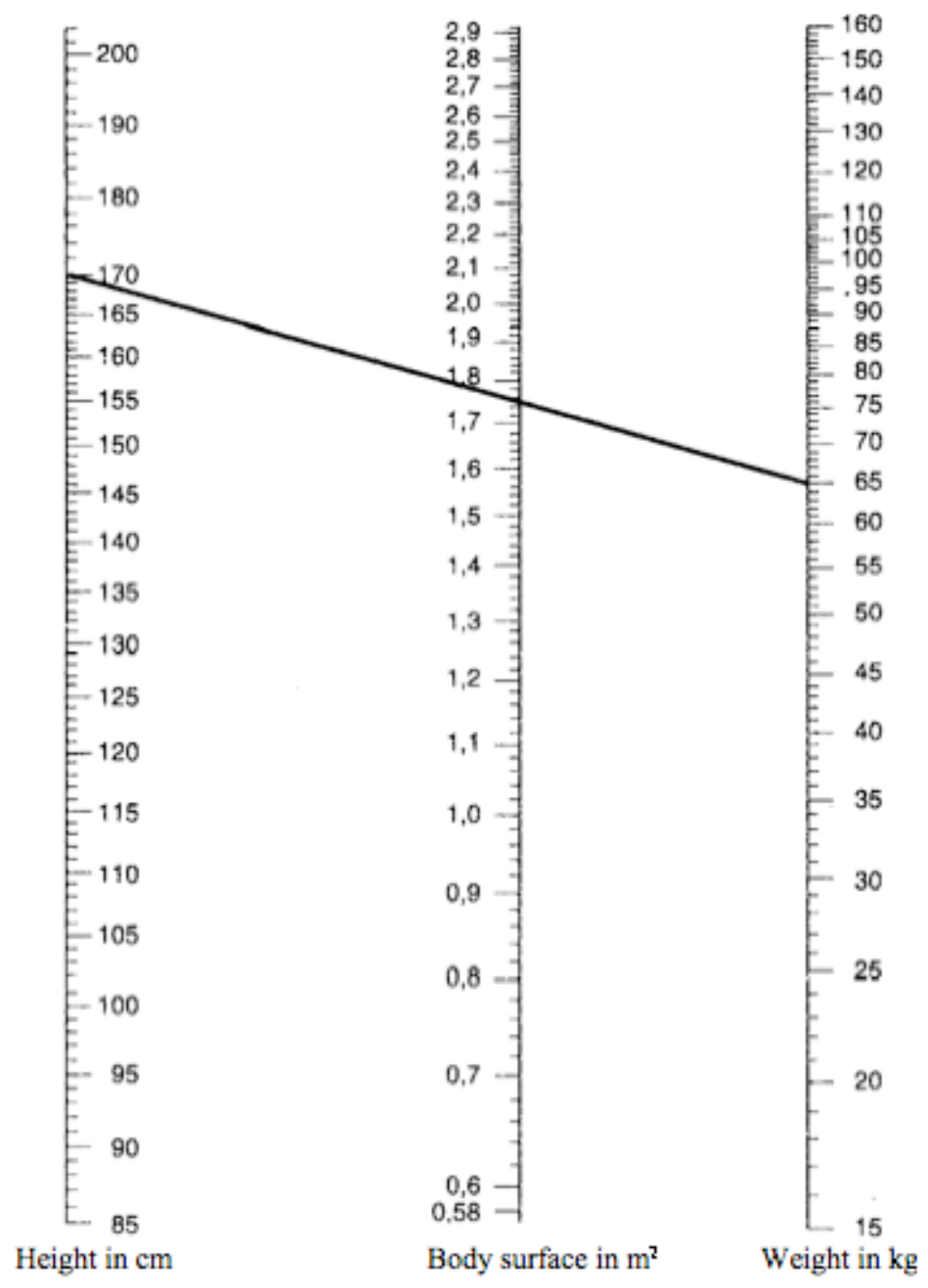

Figure 8.4. Body surface area of an adult.

\section{Graphical tables with 16-18 year olds}

As we have already seen, graphical tables (linear or circular slide rules, abaques and nomograms) have been among the instruments of calculation most commonly used before the appearance of electronic calculators, and they remain in use today in certain sectors. Consequently, it seemed to me quite pertinent to bring them back into current favour and to 
exploit them educationally to practise certain points in the programmes of study for 16-18 year olds. Indeed, for 16 year olds, they are valuable for active reading of information, emphasising the networking of registers (graphic, numerical, algebraic and geometrical), they offer a motivating area of application of the topics in the programme (affine functions, square function, reciprocal function, polynomials of the second degree, homographic functions) and they allow the practice of the first techniques of coordinate geometry in a rich context (alignment of points, intersection of straight lines or curves, graphical solution of equations). At ages 17 and 18 they can equally be used to give meanings to questions often treated in a purely technical way: representation and reading of contours, simple examples of functions of two variables, logarithmic scales.

This is why the IREM of Réunion set up a working group on abaques and nomograms with the following objectives:

- historic research of ancient graphical tables and methods of graphical representation of equations likely to be studied with the basic equipment owned by $16-18$ year olds;

- construction of precise graphical tables on large sheets of paper;

- simulation of abaques and nomograms with dynamic geometry software;

- conception and trialling practical tasks with 16-18 year olds, hinging on the use of graphical tables, both in paper form and dynamic electronic form, and on the justification of underlying mathematical properties.

It was one of the trials carried out in this context that I am going to recount here (On the Réunion IREM website accounts of other trials on abaques and nomograms can be found under the leadership of M. Alain Busser, teacher at the lycée Roland-Garros (Le Tampon)). It took place at the Bellepierre High School, at Saint-Denis in Réunion. It was Mr Jean-Claude Lise's class and I am most grateful for his welcome and collaboration. I devised and led two sessions of practical work of two hours each with the whole class (35 students). As the students had just studied the reciprocal function and the square function, I chose to base my input on the methods of graphical calculation using the hyperbola $y=\frac{1}{x}$ and the parabola $y=x^{2}$. First I will describe the activities carried out during the two sessions. I will then elaborate on the historical elements which inspired these activities.

\section{Calculating with hyperbolas}

At the start of the first session, we set off from the multiplication table, familiar to the students since primary school. While analysing this table (Figure 8.5), we wondered how we could improve it to access more numbers directly. Curves appeared linking equal products. The students, fresh from their teacher's lesson on the reciprocal function, immediately recognised hyperbolas. After a brief review of the properties of curves, we realised that they could allow the creation of a 'continuous' table. 


\begin{tabular}{||c||c|c|c|c|c|c|c|c|c|c|}
\hline $\mathbf{1 0}$ & 10 & 20 & 30 & 40 & 50 & 60 & 70 & 80 & 90 & 100 \\
\hline $\mathbf{9}$ & 9 & 18 & 27 & 36 & 45 & 54 & 63 & 72 & 81 & 90 \\
\hline $\mathbf{8}$ & 8 & 16 & 24 & 32 & 40 & 48 & 56 & 64 & 72 & 80 \\
\hline $\mathbf{7}$ & 7 & 14 & 21 & 28 & 35 & 42 & 49 & 56 & 63 & 70 \\
\hline $\mathbf{6}$ & 6 & $\mathbf{1 2}$ & 18 & 24 & 30 & 36 & 42 & 48 & 54 & 60 \\
\hline $\mathbf{5}$ & 5 & 10 & 15 & 20 & 25 & 30 & 35 & 40 & 45 & 50 \\
\hline $\mathbf{4}$ & 4 & 8 & 12 & 16 & 20 & 24 & 28 & 32 & 36 & 40 \\
\hline $\mathbf{3}$ & 3 & 6 & 9 & 12 & 15 & 18 & 21 & 24 & 27 & 30 \\
\hline $\mathbf{2}$ & 2 & 4 & 6 & 8 & 10 & 12 & 14 & 16 & 18 & 20 \\
\hline $\mathbf{1}$ & 1 & 2 & 3 & 4 & 5 & 6 & 7 & 8 & 9 & 10 \\
\hline $\mathbf{X}$ & $\mathbf{1}$ & $\mathbf{2}$ & $\mathbf{3}$ & $\mathbf{4}$ & $\mathbf{5}$ & $\mathbf{6}$ & $\mathbf{7}$ & $\mathbf{8}$ & $\mathbf{9}$ & $\mathbf{1 0}$ \\
\hline \hline
\end{tabular}

Figure 8.5. Multiplication table.

To achieve that, all it needed was to have a network of hyperbolas $x y=k$, drawn permanently on a sheet of squared paper and marked by the values of the product $k$. Armed with such a graphical table, a multiplication is carried out in the following manner (Figure 8.6): if you want to calculate the product, let us say of 6 and 2, you follow the vertical line of the equation $x=6$ and the horizontal line of the equation $y=2$ until they intersect at $A$; then we see that this point $A$ is on the hyperbola value 12 , so $6 \times 2=12$. The abaque functions in the opposite way to carry out a division: to divide 12 by 2 , you look along the hyperbola value 12 until arriving at its point of intersection $A$ with the horizontal line of the equation $y=2$; we then see that the vertical passing through $A$ corresponds to the abscissa 6 , so $12 \div 2=6$.

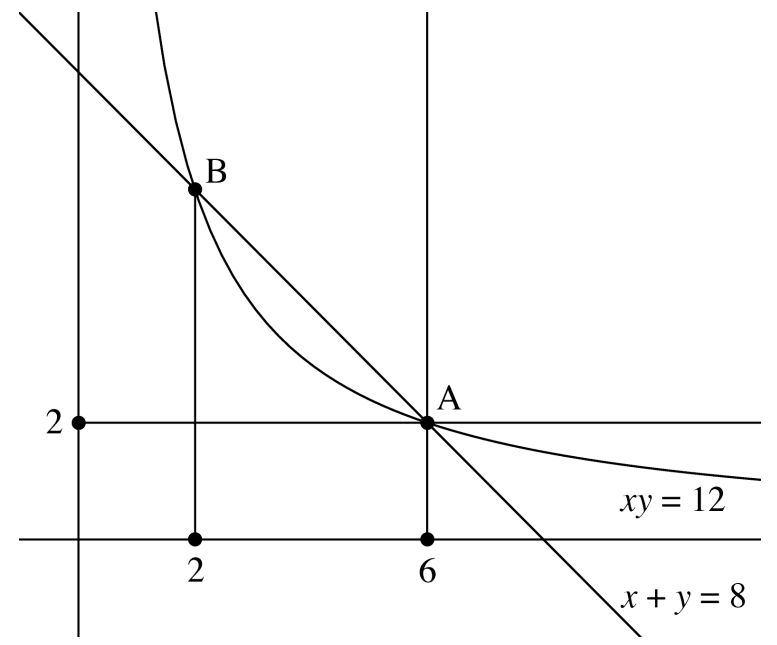

Figure 8.6. How to use a hyperbolic abaque for multiplication. 
Once the principle of this graphical multiplication table had been elucidated, the class was able to practise its use: I gave out an abaque on A3 paper to each pair of students to encourage discussion (Figure 8.7). The students settled quickly: we did a whole series of calculations, learning how to interpolate visually between the lines of the abaque when the numbers did not correspond to the lines already drawn, we estimated the accuracy, we wondered what to do when the numbers were outside the range $[0,10]$, or how to change the zone of the abaque to have greater accuracy when the number range is $[0,1]$.

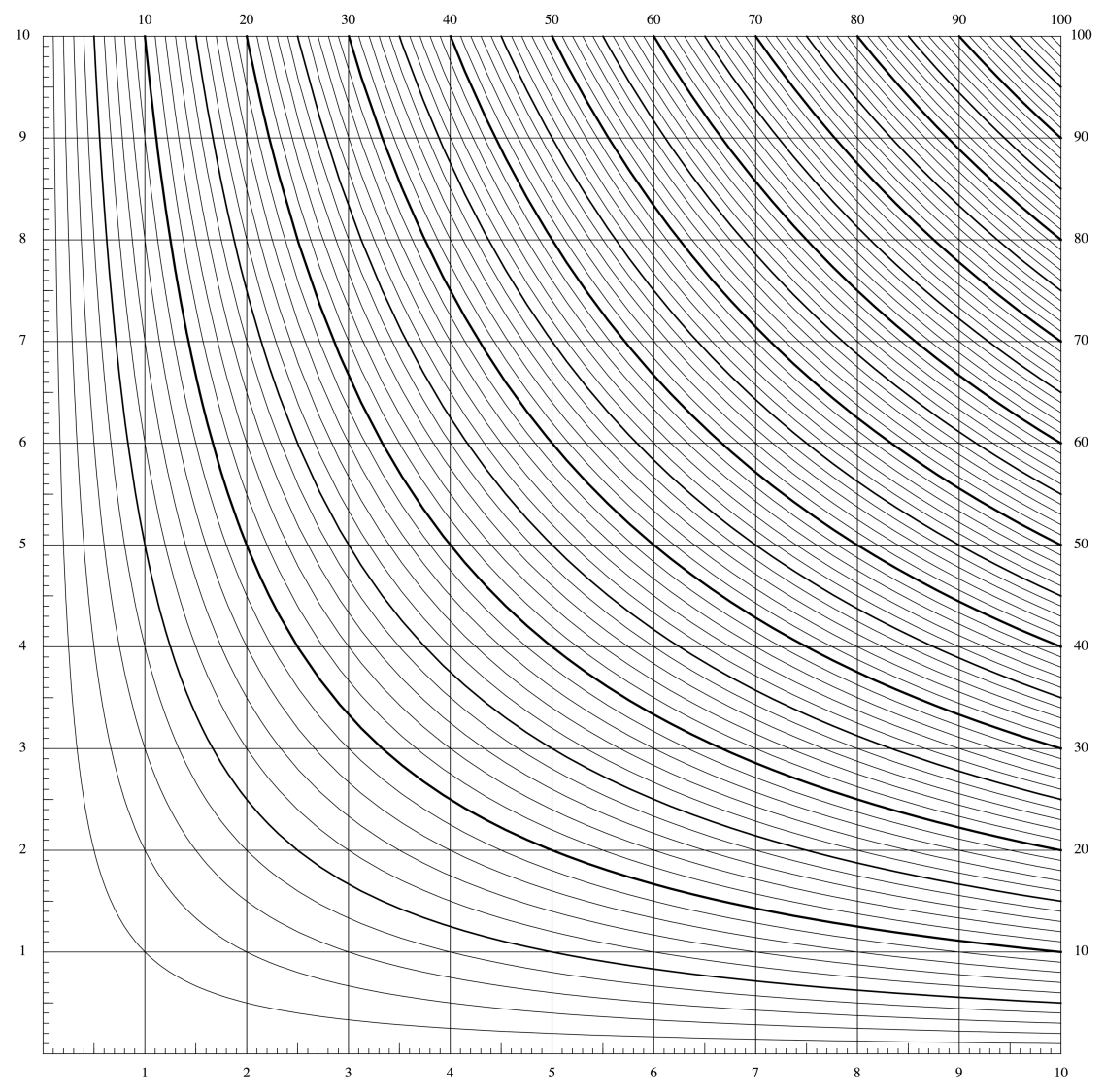

Figure 8.7. Multiplication abaque.

The first hour ended by examining an extended version of the abaque (Figure 8.8), still on A3 paper, allowing working in positive and negative numbers. It was an opportunity for a brief review of negative numbers and the rule of signs. 


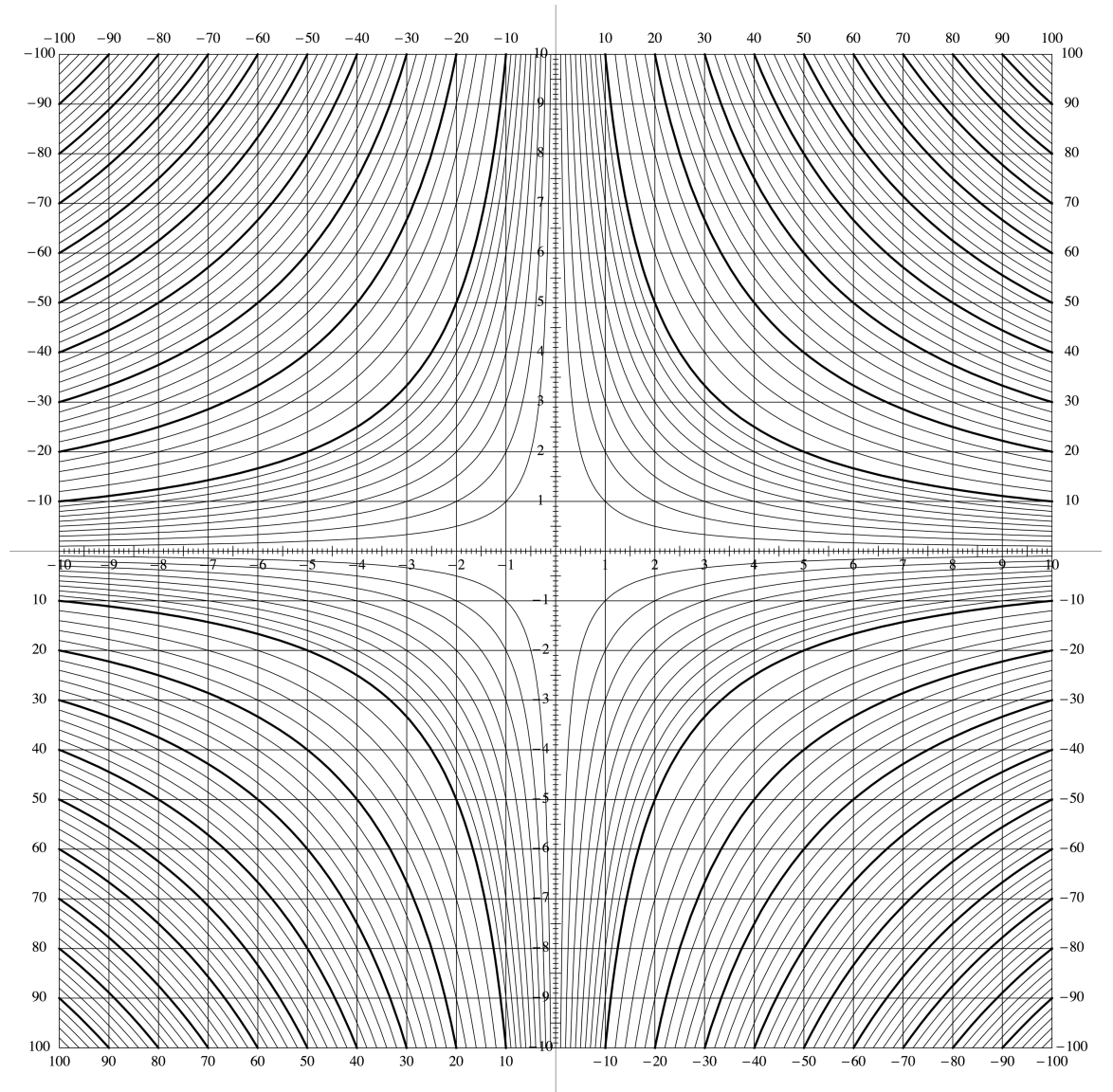

Figure 8.8. Extended multiplication abaque.

During the second hour we tackled equations of the second degree. I gave the students some second degree expressions to work with and to factorise, thus clarifying the idea that the solution of the equation $z^{2}-s z+p=0$ still amounted to finding two numbers $x$ and $y$ such that $x+y=s$ and $x y=p$. Being 16 years old, you are hardly used to working with parameters, so I had planned to work solely with numerical examples, but one student said: "You are drawing conclusions based on a few examples, but who says that it is generally true with other numbers?". Pleasantly surprised by such maturity, I therefore continued with calculations in a more general form.

Given that the abaque directly provides the hyperbola of the equation $x y=p$, it just remains to draw the straight line of equation $x+y=s$ to read off graphically the abscissae of the points of intersection of the hyperbola and straight line, and thus to solve the second degree equation $z^{2}-s z+p=0$. For example (see Figure 8.6), to solve the equation $z^{2}-8 z+12=0$, we draw the straight line of equation $x+y=8$ and we read the abscissae of its point of intersection with the hyperbola of value 12: the solutions are therefore 2 and 6 . Drawing the straight line of the equation $x+y=8$ is very simple, since all that is needed is to join the points on the axes of the coordinates $(8,0)$ and $(0,8)$. If you do not want to damage the abaque by writing on it, you can use a ruler or a taut string between these two points.

Curiously, the more the students were at ease with the hyperbolas, the more they seemed to have forgotten everything about straight lines. It took quite a time to recall how to 
calculate the equation of a straight line between two given points, but after a while we managed and the students were able to immerse themselves in the activity again. Some, having become experts, quickly solved several equations and discovered all the different possible situations (two roots, a double root, no roots). Others even protested because they did not think the abaque was accurate enough: they wanted me to make them one with many more hyperbolas!

I had intended to end this first session by solving systems such as $5 x+y=2$ and $x y=-3$, also to exploit the second and fourth quadrants of the extended abaque, but we did not have time to get that far.

\section{Calculating with parabolas}

During the second session, I suggested that the students should work with the parabola of the equation $y=x^{2}$, which they had studied recently as a curve representative of the square function. First of all, with numerical examples, I asked them to determine an equation for the straight line passing through two points $A$ and $B$ of the parabola, the first with a negative abscissa and the second positive, then to calculate the ordinate of the point of intersection, $C$, of this straight line with the $y$-axis (Figure 8.9). This work took a lot of time for the same reasons as in the first session with the hyperbolas, as the majority of students still had not completely mastered straight line equations. In spite of everything, we managed to observe that the ordinate of $C$ seemed to be the product (give or take the sign) of the abscissae of $A$ and $B$. Once this conjecture had been clarified, I took it upon myself to demonstrate the general case on the board.

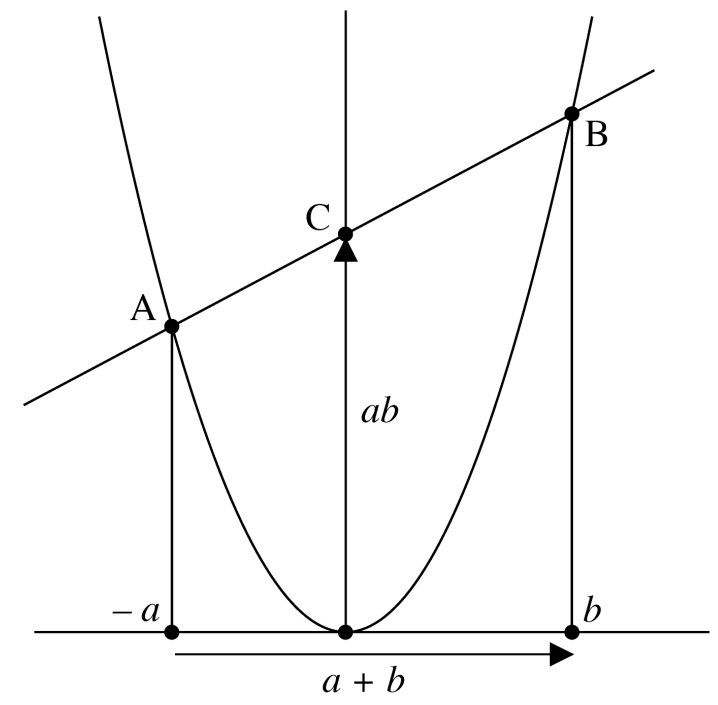

Figure 8.9. How to use a parabolic abaque for multiplication.

For that, let the three points in question be $A\left(-a, a^{2}\right), B\left(b, b^{2}\right)$ and $C(0, c)$, with $a>0$ and $b>0$. The gradient of the straight line $A B$ is $\frac{b^{2}-a^{2}}{b-(-a)}=b-a$. Using this for the gradient of $A C$ we can obtain the equation $\frac{c-a^{2}}{0-(-a)}=b-a$ and hence $c=a b$. Therefore the parabola, 
together with its vertical axis, is a graphical multiplication table. Whereas the hyperbolic multiplication table was an abaque (the result being obtained by the concurrence of three lines), the new parabolic table is a nomogram (the result being obtained by the alignment of three points). Once the points of the parabola and the vertical axis have been marked with the values of $-a, b$ and $c$, this nomogram can be used with a ruler or taut thread which is simply placed on the points $A$ and $B$, which allows the product required to be read directly on the vertical axis.

To learn how to use this table, I first gave out to each pair of students a nomogram using the parabola $y=x^{2}$ on A3 paper so they could follow the theoretical work as closely as possible. We quickly realised that this nomogram was not well adapted to calculations because of the rapid increase in the square function. I then gave them a second nomogram using the parabola $y=\frac{x^{2}}{10}$, suitably graduated (Figure 8.10) which allowed them to work efficiently in the interval $[1,10]$. This interval can always be reached by multiplying or dividing the given numbers by powers of 10 .

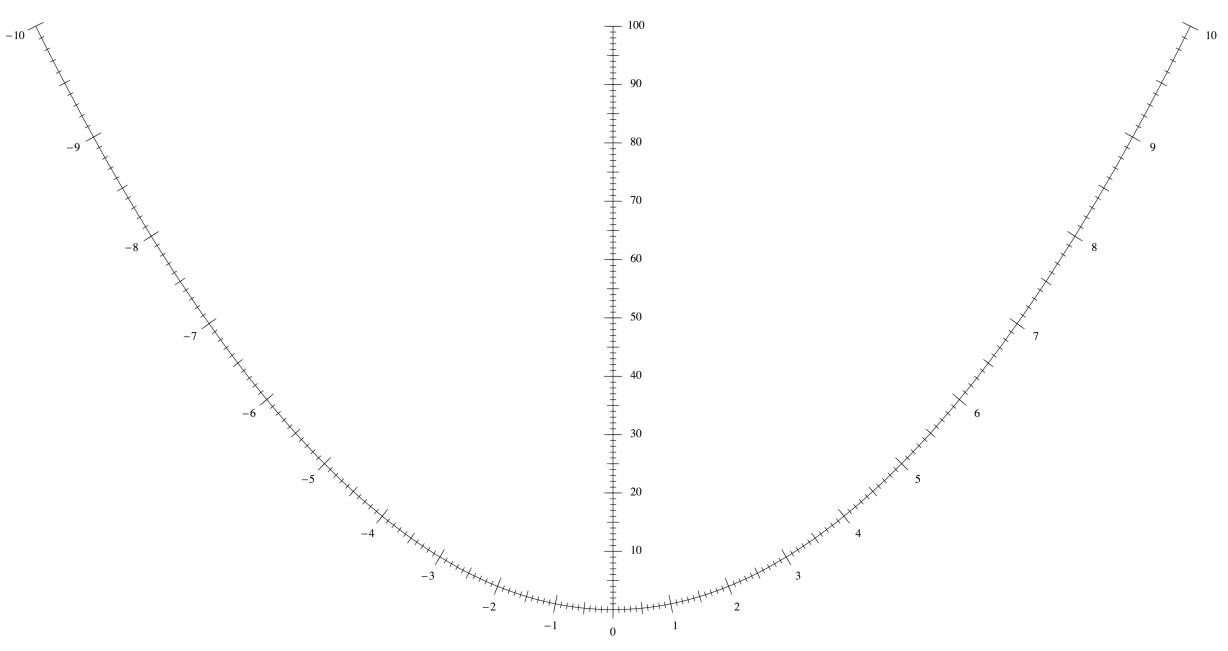

Figure 8.10. Parabolic multiplication nomogram.

The second hour was dedicated to a return to second degree equations. On the parabolic nomogram (see Figure 8.9), we have at our direct disposal from the points of the abscissae $-a$ and $b$, a graphical construction of the sum $a+b$ and the product $a b$. From it we deduce a new solution of the equation $z^{2}-s z+p=0$ : we place the ruler on point $C$ of the abscissa $p$ and we pivot the ruler around this point until we reach a sum for $a+b$ equal to $s$; the numbers $a$ and $b$ are then the required solutions.

The session ended by a comparison of the two techniques studied: hyperbolic multiplication abaque with concurrent lines versus parabolic nomogram with aligned points. The majority of students preferred the first method, the second seeming less precise. Generally speaking, they liked this work on graphical tables very much although they found it quite difficult. They even asked me when I was going to come back for other sessions of similar practical work. 


\section{Some history of graphical tables using hyperbolas and parabolas}

In conclusion, let us give some information on the historic sources of the previously described activities. As already mentioned earlier, the hyperbolic multiplication abaque is an invention of Louis-Ézéchiel Pouchet. The context is that of the French Revolution's attempts to impose a new system of weights and measures. To help the population get used to the reform, article 19 of the law of 18 Germinal year III of the French Revolution prescribed a simplification of the conversion tools: "Instead of the conversion tables between the old and new measures, which had been ordered by the decree of 8 May 1790, it will be done by graphical scales to estimate those conversions without needing any calculation." It was in response to this that Pouchet drew up a book on metrology which went through three editions, including graphical tables which became more and more elaborate. In the third edition of his book (1797), he suggested real abaques for the first time, that is, graphs from which you could read the results of calculations directly without any manipulation (Pouchet, 1797). These tables allowed basic calculations to be carried out: addition, subtraction, multiplication, division, squaring, square rooting, the rule of three and converting units.

Then we had to wait until 1891 for Lieutenant Julius Mandl of the Imperial Corps of Austrian Engineers to come up with the idea of using Pouchet's multiplication abaque to solve equations of the second, third and fourth degrees (Mandl, 1891). Mandl's article was almost translated into English in 1893 by Major W. H. Chippindall of the Royal Engineers (Chippindall, 1893).

The solving of the second degree equation $x^{2}+A x+B=0$, by the intersection of the hyperbola $x y=B$ given by the abaque and the straight line $x+y=-A$, shown by a ruler or a taut thread was explained earlier. For the third degree equation $x^{3}+A x^{2}+B x+c=0$, the roots prove the relationships:

$$
\left\{\begin{array}{l}
x_{1}+x_{2}+x_{3}=-A \\
x_{1} x_{2}+x_{1} x_{3}+x_{2} x_{3}=B \\
x_{1} x_{2} x_{3}=-C .
\end{array}\right.
$$

Supposing $x_{2}+x_{3}=z$ and $x_{2} x_{3}=y$, the previous system becomes

$$
\left\{\begin{array}{l}
x_{1}+z=-A \\
x_{1} z+y=B \\
x_{1} y=-C
\end{array}\right.
$$

The elimination of $z$ between the first two equations leads to the relationship $y=x_{1}{ }^{2}+A x_{1}+B$. So the root $x_{1}$ appears as being the abscissa of a point of intersection of the equation $x y=-C$ and of the parabola with equation $y=x^{2}+A x+B$. Through symmetry it is the same for the other two roots $x_{2}$ and $x_{3}$. The previous parabola with equation $y-\left(B-\frac{A^{2}}{4}\right)=\left(x+\frac{A}{2}\right)^{2}$ has its vertex at $\left(-\frac{A}{2}, B-\frac{A^{2}}{4}\right)$. For the graphical solution we have a parabola permanently drawn on a transparent sheet. Therefore all you have to do is to place this parabola on the abaque with its vertex at the point with coordinates $\left(-\frac{A}{2}, B-\frac{A^{2}}{4}\right)$ and 
read the coordinates of where it intersects the hyperbola with equation $x y=-C$ on the abaque. This solution of the third degree equation, undoubtedly too difficult for a class of 16 year olds, should be beneficial for older students. In his article, Mandl finally explains how to solve the fourth degree equation thanks to Pouchet's abaque and the transparency with the fixed parabola. Without going into details, it is enough to say that we resort in a classical manner to the successive solving of a third degree equation and several second degree equations by methods we have already seen.

Let us move on to the origins of the parabolic multiplication nomogram, used during the second session of practical work. For the first time we meet something like it in 1841, in the work of August Ferdinand Möbius (1790-1868) (Figure 8.11): on each of the parabolas shown in the table, if we draw a straight line joining two of the numbers marked on the parabola then the straight line passes through their product on the line at the top of the table (Möbius, 1841). However it does not seem that Möbius' work was noticed, nor that it had any influence on later authors.

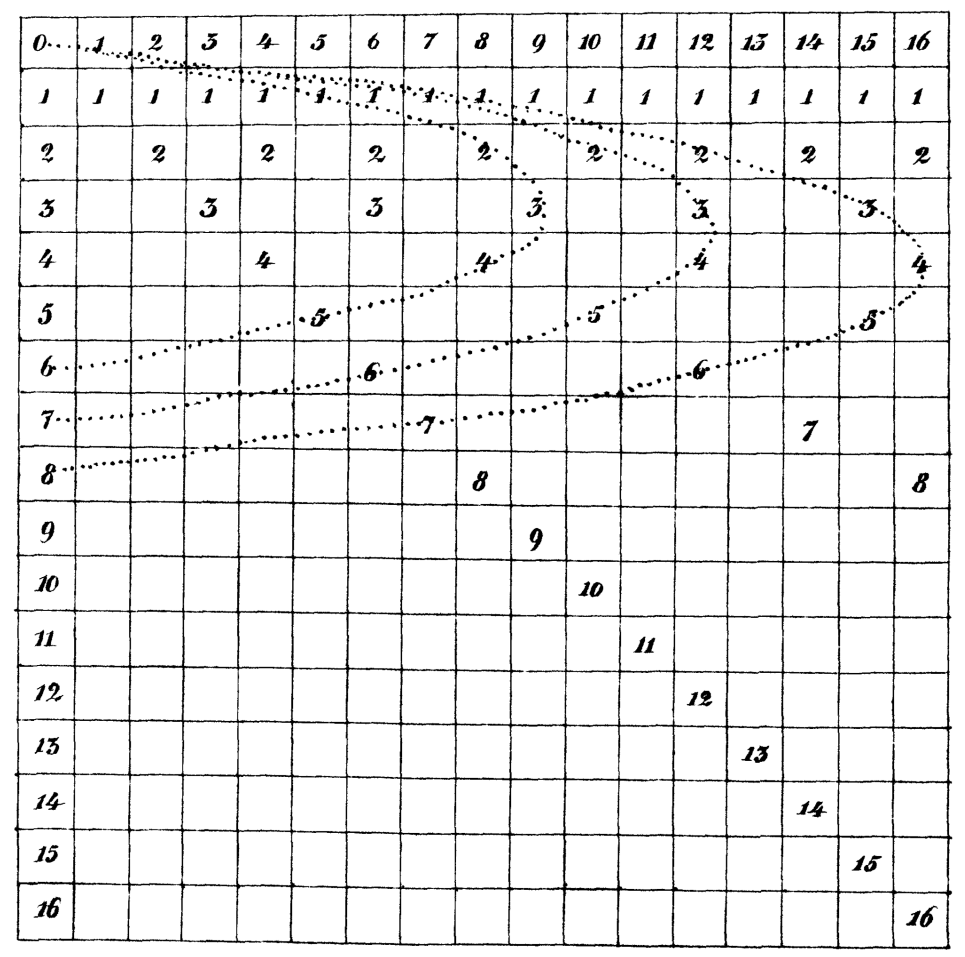

Figure 8.11. One of Möbius' tables from (Möbius, 1841).

Then it was the engineer John Clark (A person about whom we know practically nothing except that he was a mathematics teacher at the Polytechnic School in Cairo at the time.) who brought to light in 1905 the parabolic multiplication nomogram as we presented it to the 16 year old students (Clark, 1907, 1908). He achieved it by a seemingly complex route but whose value lies in the fact that this method can be used for a whole range of relationships with three variables. The main idea is to try to construct nomograms using a straight line and a doubly marked conic, called 'conic nomograms'. In the case of the multiplication $\alpha \beta=\gamma$, we can write, when $\alpha$ and $\beta$ are distinct: 


$$
\begin{aligned}
\alpha \beta=\gamma \Leftrightarrow \exists(x, y) & \left\{\begin{array} { l } 
{ x = \alpha \beta } \\
{ y = - \alpha - \beta } \\
{ x = \gamma }
\end{array} \Leftrightarrow \exists ( x , y ) \left\{\begin{array}{r}
\alpha^{2}+y \alpha+x=0 \\
\beta^{2}+y \beta+x=0 \\
-\gamma+x=0
\end{array}\right.\right. \\
& \Leftrightarrow\left|\begin{array}{lll}
\alpha^{2} & \alpha & 1 \\
\beta^{2} & \beta & 1 \\
-\gamma & 0 & 1
\end{array}\right|=0 .
\end{aligned}
$$

The nullity of this last determinant fully expresses the alignment of the three points, of which two, marked by $\alpha$ and $\beta$, are on the parabola with equation $y=x^{2}$ and whose third, marked by $-\gamma$, lies on the $y$-axis.

\section{In conclusion}

This trial reassured me that nomography is a choice area for rich and attractive practical activities with students of age 16 onwards. Practising the principle notions of the programme of study in a non-routine context, permanent interaction between algebra and geometry, simple and inexpensive materials and the clear enthusiasm of the students are so many arguments which, I hope, will convince teachers to explore this avenue.

Acknowledgements: My thanks to Janet and Peter Ransom, who translated my text from the French.

\section{References}

Chippindall, W.H. (1893). Graphic solution for equations of the second, third and fourth powers, Professional Papers by the Corps of Royal Engineers, Vol. 19, pp. 177-187.

Clark, J. (1907, 1908) Théorie générale des abaques d'alignement de tout ordre, Revue de mécanique, Vol. 21, pp. 321-335, pp. 576-585; Vol. 22, pp. 238-263, pp. 451-472.

Khovanski, G.S. (1979). Éléments de nomographie. Embarek, D. (translator). Moscow: Mir.

Mandl, J. (1891). Graphische Auflösung von Gleichungen zweiten, dritten und vierten Grades, Mitteilungen über Gegenstände des Artillerie- und Geniewesens, Vol. 22, pp. $133-141+$ pl. 14 .

Möbius, A.F. (1841). Geometrische Eigenschaften einer Factorentafel, Journal für die reine und angewandte Mathematik, Vol. 22, pp. 276-284 + pl. I.

Pouchet, L.-É. (1797-an V). Métrologie terrestre, ou Tables des nouveaux poids, mesures et monnoies de France. Nouvelle édition, considérablement augmentée. Rouen: Guilbert $\&$ Herment.

Ocagne, M. d'. (1891). Nomographie. Les calculs usuels effectués au moyen des abaques. Essai d'une théorie générale. Règles pratiques. Exemples d'application. Paris: Gauthier-Villars.

Ocagne, M. d'. (1899). Traité de nomographie. Théorie des abaques, applications pratiques. Paris: Gauthier-Villars. 
Ocagne, M. d'. (1921). Traité de nomographie. Étude générale de la représentation graphique cotée des équations à un nombre quelconque de variables, applications pratiques (2nd ed.). Paris: Gauthier-Villars.

Tournès, D. (2003). Du compas aux intégraphes: les instruments du calcul graphique, Repères IREM, $\mathrm{n}^{\circ}$ 50, pp. 63-84.

Tournès, D. (2005). Constructions d'équations algébriques, Repères IREM, n 59 , pp. 69-82.

Soreau, R. (1921). Nomographie ou Traité des abaques (2 Vol.). Paris: Chiron. 